\title{
Genetic characterization of Spanish lentil landraces (Lens culinaris Medik.) by biochemical markers
}

\author{
M.D. Cristóbal and B. Herrero* \\ University of Valladolid, Escuela de Ingenierías Agrarias, \\ Avenida de Madrid 57, 34004 Palencia, Spain. \\ Received: 16-02-2016 \\ Accepted: 21-04-2016
}

DOI: $10.18805 /$ ijare.v50i3.10743

\section{ABSTRACT}

Diversity analysis and a genetic structure study of 25 lentil landraces (Lens culinaris Medik.) from the northern east part of the Iberian Peninsula were carried out. 8 isozymes: PGI, PRX, LAP, 6PGD, GOT, SKDH, PGM and ME, have been used for this purpose having found 17 loci for them, with 52.94\% polymorphic loci and a total amount of 21 alleles. All populations show between 18 and 26 alleles. Genetic distance (D) was 0.123 . Diversity parameters show similar or higher levels compared to other autogamous plant populations. They show an heterozygote defect. Coefficient of homozygotes among populations $\left(\mathrm{G}_{\mathrm{ST}}\right)$ value 0.414 , was similar to Inbreeding coefficient among populations $\left(\mathrm{F}_{\mathrm{ST}}\right)$ that was 0.454 . Main component analysis showed that the most important isozymes in the characterization process were GOT-3 and PGM-2. Four groups of populations were obtained by cluster analysis. This information reveals new data for improving their use in the germplasm banks for crop programs.

\section{Key words: Genetic diversity, Genetic resources, Isozymes, Lens culinaris, Lentil landraces.}

\section{INTRODUCTION}

Lentil is to be considered one of the oldest crops, being archaeological signs, found in Mureybit, in the North of Syria, that allow to date back the crop 8,500 to 9,000 years old. The crop spread to other areas 3,000 years ago (Zohary and Hofp, 1994). In the Iberian peninsula it dates back to the bronze age. In lentils cultivated in Spain, most of them local varieties, we can differentiate two types according to their morphology based on seed characteristics: Macrosperma (weigh of 100 seeds $>4.5 \mathrm{~g}$ ) and Microsperma. Two morphotypes stand out within this last group, a lentil called Pardina, with brown testa with variable pattern, and another one named Verdina which presents olive green testa with large black pattern. Both morphotypes are classified as botany varieties: variabilis and dupuyensis.

Landraces are collected and preserved by gene banks and they represent a valuable contribution to establish the core collection. These collections have a representative variation of the cultivated species and in order to be able to use them in future breeding programs, they should be characterized and evaluated. In order to preserve these varieties, within characterization, it is necessary to know their genetic variability and the genetic structure of these populations, for this purpose have been used morphological markers (Erdogan, 2015), molecular markers (Bacchi et al., 2010, Andeden et al., 2015), or both simultaneously (Jains et al., 2014). Every method to obtain a collection in which species variability is represented, starts by preparing uniform groups of the preserved material based on morpho-agronomic characters, biochemical ones or DNA information (Lázaro and Aguinagalde, 2006).

The first determinant of the populations genetic structure is the reproductive system. Lentils present a high level of autogamy (Ferguson and Robertson, 1996).

Associations between different loci alleles, not due to bound, are gene combinations that remain because of chance or, if they interact favorably, by means of selection. These multilocus genotypes are the result of a not very effective recombination, such as in populations which are mainly autogamous and may represent an adaptive role (Pérez-Vega and García, 1997). Studies based on protein analysis, such as isozymes, for germplasm characterization, have decreased in the last years, face to the boom that studies based on the use of molecular markers have had. Without any doubt DNA markers have a higher potential regarding polymorphism detection. Isozymes as genetic markers could show genetic variation of protein among or above population levels (Bacchi et al., 2010). The differences of enzymatic proteins are usually directly related to organism metabolic activity. Therefore, results of isozyme analysis cannot only estimate the genetic structure of a population, but can also be used to compare relevant performance traits with specific isozymes among individuals or stocks in genetic improvement programs (Sharma et al., 2008). 
The aims of the present study are: (1) to study variability and lentil landraces genetic structure using isozymes as markers, (2) to examine genetic differentiation by cluster analysis based on allele frequencies of isozyme gene loci.

\section{MATERIALS AND METHODS}

Experimental material: Plant material of this study consisted of 25 local varieties of Lens culinaris Medik. from Castilla y León, in the North West of Spain. Twenty three samples were provided by the germplasm bank of CRF-INIA (Plant Genetic Resources Center, National Institute of Agricultural and Food Technology, Madrid) and two of them were supplied by a farmer. Samples weigh ranged from 100 to $200 \mathrm{~g}$. Table 1 shows the numbers or names given to the accessions, the town and province of origin and their belonging to one of the defined above types of seed, as well as the original agro-climatic zone.

Electrophoretic assays: For the characterization with isozymes, seeds were germinated and plants breeded in vermiculite for 15 days, under a 16 light hour period at $22^{\circ} \mathrm{C}$. An in vitro lentil crop (cultivar Ángela) was cultivated as pattern, being present in every electrophoresis that was carried out.

Two hydrolyzed starch gels with $11 \%$ concentration dissolved in the adequate buffers were used. We used two buffer systems for gels and trays: system 1, Histidine-Tris citric (Selander et al., 1971) and system 2, Tris citrateLithium borate (Cardy et al., 1980). One gel from system 1 and two from system 2 were analyzed in each electrophoresis.

Three leaflets were macerated in $0.5 \mathrm{ml}$ distilled water for each plant sample in individual wells. Whatman papers $\mathrm{n}^{\circ} 3$ of $0.5 \mathrm{~mm}$ thickness $\mathrm{x} 1 \mathrm{~cm}$ diameter, these were inserted in the gel where added to the macerated material. Fifty plants per local variety were analyzed. Electrophoresis conditions were $80 \mathrm{~mA}$ for the histidine system and $350 \mathrm{~V}$ for the lithium one, for 4-6 hours, until the front part had moved about $10 \mathrm{~cm}$. In the different systems gels slices were stained for the following enzymes, system 1 for: 6 Phosphogluconate dehydrogenase (6PGD) E.C.: 1.1.1.44. (Enzyme Commission Numbers), Sikimate dehydrogenase (SKDH) E.C.: 1.1.1.25.

In system 2: Phosphoglucoisomerase (PGI) E.C.: 5.3.1.9., Cathodic peroxidases (PRX-c) E.C.: 1.11.1.7., Leucin aminopeptidase (LAP) E.C.: 3.4.11.1., Glutamate oxaloacetate transaminase (GOT) E.C.: 2.6.1.1., Phosphoglucomutase (PGM) E.C.: 5.4.2.2. and Malic enzyme (ME) E.C.: 1.1.1.40. Codominant monogenic inheritance of all these enzymes were contrasted previously.

Table 1: Lentil landraces used in this study. Register number, locality, province, agroclimatic zone (AZ): I (Mountain León), II (detritus high plateau), III (leonés high plateau), IV (limestone high plateau), altitude $(\mathrm{H})$, average temperature of the coldest month in ${ }^{\circ} \mathrm{C}$ (TCM), frost period (FP) and average annual precipitation in mm (AAP), for each region. Type of seed: lentil Microsperma Pardina, $(\mathrm{P})$, Microsperma Verdina (V) and Macrosperma (M).

\begin{tabular}{|c|c|c|c|c|c|c|c|c|}
\hline Accession & Locality & Province & $\mathbf{A Z}$ & $\mathbf{H}$ & TCM & $\mathbf{F P}$ & $\mathbf{A P P}$ & Seed \\
\hline 2058 & Posada de Valdeón & León & I & 939 & $7-10$ & $8-10$ & $700-1200$ & $\mathrm{P}$ \\
\hline 8697 & Matallana de Torío & León & & 1013 & & & & $\mathrm{~V}$ \\
\hline 8698 & Riaño & León & & 1048 & & & & $\mathrm{P}$ \\
\hline 8688 & Cistierna & León & & 951 & & & & $\mathrm{~V}$ \\
\hline 4245 & Valdepolo & León & II & 803 & $8-12$ & $6-8$ & $500-600$ & $\mathrm{P}$ \\
\hline BAUI & Respenda de la Peña & Palencia & & 990 & & & & $\mathrm{P}$ \\
\hline BAUII & Riosmenudos de la Peña & Palencia & & 990 & & & & $\mathrm{P}$ \\
\hline 16344 & Pino del Río & Palencia & & 992 & & & & $\mathrm{P}$ \\
\hline 8701 & Valencia de don Juan & León & III & 765 & $8-11$ & $6-8$ & $400-500$ & $\mathrm{P}$ \\
\hline 16346 & Izagre & León & & 792 & & & & $\mathrm{P}$ \\
\hline 4246 & Matadeón de los Oteros & León & & 858 & & & & $\mathrm{~V}$ \\
\hline 11076 & Sahagún & León & & 816 & & & & $\mathrm{~V}$ \\
\hline 11083 & Sahagún & León & & 816 & & & & $\mathrm{P}$ \\
\hline 16345 & Grajal de Campos & León & & 800 & & & & $\mathrm{P}$ \\
\hline 4244 & Grajal de Campos & León & & 800 & & & & $\mathrm{P}$ \\
\hline 11075 & Vallecillo & León & & 839 & & & & $\mathrm{P}$ \\
\hline 11082 & Nava de los Oteros & León & & 853 & & & & $\mathrm{~V}$ \\
\hline 11079 & Valladolid & Valladolid & IV & 691 & $8-11$ & $6-8$ & $400-500$ & $\mathrm{M}$ \\
\hline 11080 & Valladolid & Valladolid & & 691 & & & & $\mathrm{M}$ \\
\hline 11081 & Valladolid & Valladolid & & 691 & & & & $\mathrm{P}$ \\
\hline 11078 & Valladolid & Valladolid & & 691 & & & & $\mathrm{M}$ \\
\hline 11074 & Villanubla & Valladolid & & 843 & & & & $\mathrm{M}$ \\
\hline 19696 & Villamuriel de Cerrato & Palencia & & 725 & & & & $\mathrm{M}$ \\
\hline 22153 & Castrojeriz & Burgos & & 808 & & & & $\mathrm{~V}$ \\
\hline 22154 & Castrojeriz & Burgos & & 808 & & & & $\mathrm{P}$ \\
\hline
\end{tabular}


Statistical analysis: All the strip patterns in each enzymatic system were identified for every population. Genetic interpretation was done so the number of loci and alleles present in them were identified after obtaining these strip patterns. Used nomenclature is the following: the fastest isozyme is named 1 and after 2,3..., for the slower ones. Using the nomenclature proposed by Tahir and Muehlbauer (1995), the strips in every zone are named as A, the most anodic one, B, C, etc., consecutively for the most cathodic ones. With the identified loci and alleles data we did a data matrix that was used to carry out different statistic analysis, using the program POPGENE 1.31 (Yeh et al., 1999).

Intrapopulation genetic parameters that were found, using both polymorphic and monomorphic loci were: allele frequencies, genotype frequencies, number of alleles per locus (A), effective number of alleles $\left(\mathrm{N}_{\mathrm{e}}\right)$, percentage of polymorphic loci $(\mathrm{P})$ and Nei genetic diversity $(\mathrm{N})$.

It is necessary to study how variety spreads in and among populations in order to describe genetic diversity in a set of populations. Inbreeding coefficient among populations $\left(\mathrm{F}_{\mathrm{ST}}\right)$, Genetic distance among populations $\left(\mathrm{D}_{\mathrm{ST}}\right)$, and Coefficient of homozygotes among populations $\left(\mathrm{G}_{\mathrm{ST}}\right)$ were calculated.

A cluster analysis was carried out with the genetic distances data obtained using UPGMA (Unweighted PairGroup Using an Arithmetic Average) procedure. Allelic frequencies were analyzed with a principal component analysis, to determine which isozymes were more important in the characterization of the local varieties, and set the most useful isozymes in the characterization. These analyses were performed using SPSS statistics software (2006)

\section{RESULTS AND DICUSSION}

Figure 1 represents the obtained strip pattern description for each enzymatic system. A genetic interpretation of them based on bibliography is proposed, and if bibliography does not exist, the most logical solution based on polypeptide chains that conforms the enzyme and its cellular compartmentalization is proposed.

The results of genetic interpretation made on 8 enzymatic systems concluded in the identification of 17 loci, 9 of which are polymorphic (at the 0.95 criterion), PGI-1, LAP-1, 6PGD-1, GOT-2, GOT-3, SKDH-1, PGM-2, ME-1 and PRX-c, which means $52.94 \%$ of polymorphic loci for all populations.

In Table 2 polymorphism respects to analyzed isozymes, for each population can be observed, ranging from $5.88 \%$ in population 8697 to $47.06 \%$ of 22154 and 11074 . Loci which turned out to be polymorphic in more populations were the ones that govern PRX, in the 25 populations, SKDH-1 in 21 of them and GOT-3 y ME-1 in 17 populations. The average of polymorphic loci per population was $29 \%$. No monomorphic populations were found. Polymorphism percentage obtained is similar to the one found by Pinkas $e t$ al. (1985), in different species of the genre Lens (53\%) and Ferguson et al. (1998) (54\%) in the subspecies orientalis, and was higher to the polymorphism found by Erskine and Muehlbauer (1991) and Ferguson et al. (1998) in the subspecies culinaris from different geographical origins. Average percentage of polymorphic loci per population is (27.2\%), similar to the one obtained by Hamrick and Godt (1997) when they studied autogamous plant populations. Additionally with respect to the used loci polymorphism, Rosa and Jouve (1992) verify gene polymorphism high level in PRX and GOT-3 in their study of Lens culinaris accessions

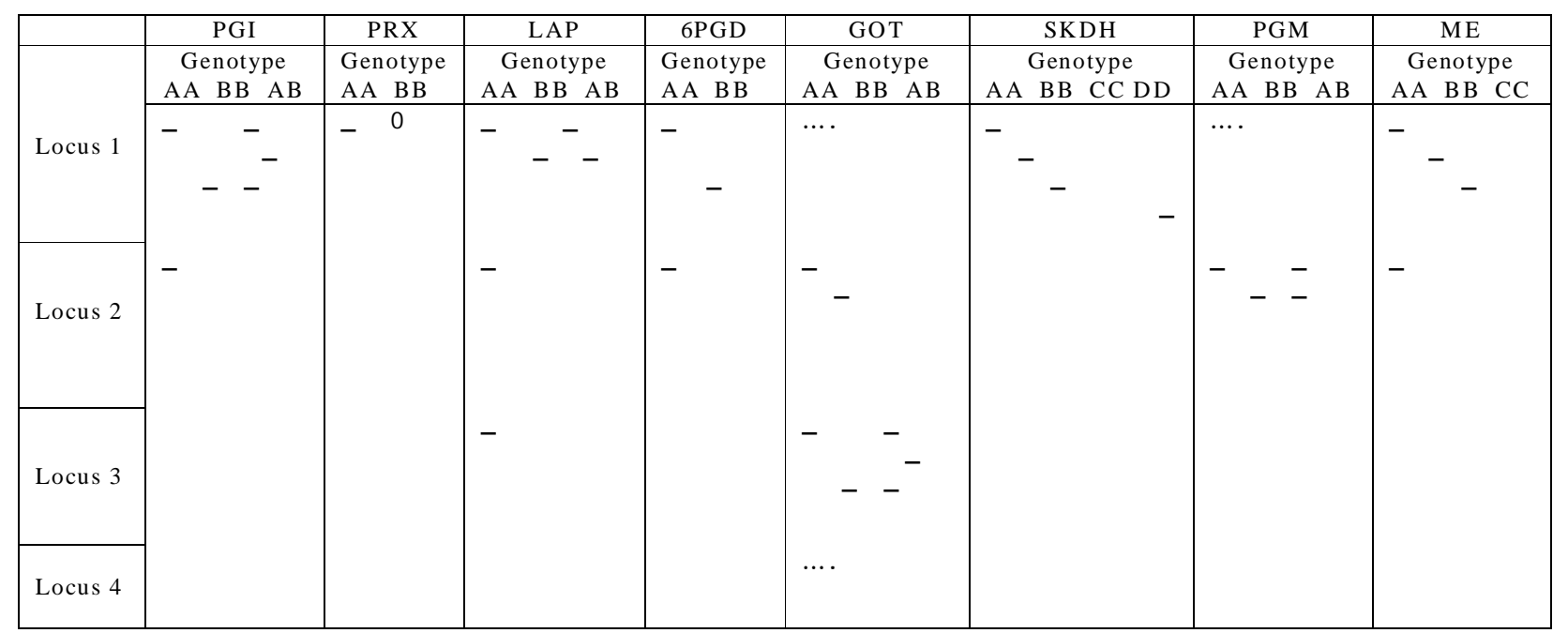

Fig 1: Schematic representation of zymograms obtained for the eight isozymes. 0 represents a null allele. Discontinuous lines shows isozymes very slightly staines. PGI (phosphoglucoisomerase), PRX (catodic peroxidase), LAP (leucinaminopeptidase), 6PGD (6-phosphogluconate dehydrogenase), GOT (glutamate oxalacetic transminase), SKDH (sikimate dehydrogenase), PGM (phosphoglucomutase), ME (malic enzyme). 
Table 2: Population genetic variability of 25 landrace populations of Spanish lentil at 8 isozymes. Percentage of polymorphic loci (P), Nei's genetic diversity (N), Number of allele per locus (A) and Effective number of alleles $\left(\mathrm{N}_{\mathrm{e}}\right)$.

\begin{tabular}{lcccc}
\hline Accession & $\mathbf{P}$ & $\mathbf{N}$ & $\mathbf{A}$ & $\mathbf{N e}$ \\
\hline 8697 & 5.88 & 0.013 & 1.058 & 1.017 \\
11081 & 17.65 & 0.045 & 1.176 & 1.073 \\
11083 & 17.65 & 0.043 & 1.235 & 1.066 \\
11076 & 17.65 & 0.064 & 1.235 & 1.108 \\
8701 & 23.53 & 0.091 & 1.266 & 1.151 \\
8688 & 23.53 & 0.068 & 1.235 & 1.109 \\
4246 & 23.53 & 0.023 & 1.251 & 1.026 \\
4245 & 23.53 & 0.046 & 1.235 & 1.059 \\
4244 & 23.53 & 0.054 & 1.294 & 1.087 \\
11075 & 29.41 & 0.086 & 1.294 & 1.144 \\
2058 & 29.41 & 0.065 & 1.375 & 1.096 \\
BAUII & 29.41 & 0.086 & 1.352 & 1.131 \\
16346 & 29.41 & 0.086 & 1.411 & 1.121 \\
BAUI & 29.41 & 0.050 & 1.411 & 1.075 \\
8698 & 35.29 & 0.113 & 1.352 & 1.179 \\
11078 & 35.29 & 0.073 & 1.411 & 1.101 \\
11079 & 35.29 & 0.067 & 1.411 & 1.090 \\
11082 & 35.29 & 0.082 & 1.411 & 1.128 \\
16344 & 35.29 & 0.081 & 1.411 & 1.121 \\
22153 & 35.29 & 0.073 & 1.470 & 1.114 \\
16345 & 35.29 & 0.094 & 1.529 & 1.146 \\
19696 & 35.29 & 0.080 & 1.529 & 1.151 \\
11080 & 41.18 & 0.102 & 1.529 & 1.163 \\
22154 & 47.06 & 0.109 & 1.470 & 1.166 \\
11074 & 47.06 & 0.118 & 1.529 & 1.165 \\
Mean & $\mathbf{2 9 . 6 4}$ & $\mathbf{0 . 0 7 2}$ & $\mathbf{1 . 3 5 0}$ & $\mathbf{1 . 1 1 2}$ \\
\hline & & & &
\end{tabular}

with different origins using isozymes, these genes are also highly polymorphic in our study.

All Chi-2 test of departure from Hardy-Weinberg expectations of genotype frequencies under panmixia were significant at $95 \%$ probability.

From the 21 alleles observed in all populations for the studied isozymes, 13 can be considered as common widespread according to the classification of Brown (1989),
7 as rare widespread and 1, A of GOT as rare localized only appears in 4 populations belonging to zone IV of the study, limestone high plateau.

All populations show an allele number ranging between 18 alleles (population 8697) and 26 (11074, 11080, $16345,19696)$. The average number of alleles per locus varies between 1.058 of population 8697 and 1.509 of 11074 .

Table 2 shows that effective number of alleles ranges between 1.017 and 1.179 . Genetic diversity index values found range between 0.013 (in population 8697 ) and the highest one found of 0.118 (11074). Values found for the average allele number per locus are lower to the ones found by Ferguson et al. (1998) that ranged from 1.143 to 1.714. These authors used lentils from different geographical origin that might justify a higher value for this parameter. In the set of populations the average allele number per locus is 1.351, higher to the one found by Erskine and Muehlbauer (1991) that was 1.201 in Chilean lentil populations, 1.191 in Greek populations and 1.181 in Turkish populations. These data confirm that the studied populations are very diverse showing a high allelic variety in spite of the size, not very extense, of the origin area.

Regarding coefficients of genetic variation within and among populations shown in Table 3, we have calculated $\mathrm{D}_{\mathrm{S}}=0.072$ (Genetic distance of the population), $\mathrm{D}_{\mathrm{T}}=0.123$ (Total genetic distance) and $\mathrm{D}_{\mathrm{ST}}=0.051$ (Genetic distance among populations). Differentiation coefficient $\mathrm{G}_{\mathrm{ST}}$ (Coefficient of homozygotes among populations) has been calculated resulting $0.414 . \mathrm{F}_{\mathrm{ST}}$ (Inbreeding coefficient among populations) values shown in Table 3 range from 0.081 in locus ME-1 and 0.768 of GOT-3. The average was 0.454 . Ferguson and Robertson (1996) carried out a genetic diversity study using different species of Lens genus. For the set of Lens culinaris populations they obtained genetic diversity value of 0.161 , higher to the one found in our study that was 0.123 . Nevertheless, in the previous study the lentils used had very different origins (India, Afghanistan, Chile) which somehow could justify this high value obtained.

Table 3: Diversity distribution parameters within and among populations. Total genetic distance $\left(\mathrm{D}_{\mathrm{T})}\right.$, Genetic distance of the populations $\left(D_{S}\right)$, Genetic distance among populations $\left(D_{S T}\right)$, Coefficient of homozygotes among populations $\left(\mathrm{G}_{\mathrm{ST}}\right)$, Total inbreeding coefficient $\left(\mathrm{F}_{\mathrm{IT}}\right)$, Inbreeding coefficient within populations $\left(\mathrm{F}_{\mathrm{IS}}\right)$, Inbreeding coefficient among populations $\left(\mathrm{F}_{\mathrm{ST}}\right)$.

\begin{tabular}{|c|c|c|c|c|c|c|c|}
\hline LOCUS & $\mathbf{D}_{\mathrm{T}}$ & $\mathbf{D}_{\mathrm{s}}$ & $\mathbf{D}_{\mathrm{ST}}$ & $\mathbf{G}_{\mathrm{ST}}$ & $F_{\text {IT }}$ & $F_{\text {IS }}$ & $\mathbf{F}_{\mathrm{ST}}$ \\
\hline PGI-1 & 0.081 & 0.068 & 0.014 & 0.175 & 0.991 & 0.990 & 0.083 \\
\hline PRX & 0.374 & 0.331 & 0.042 & 0.114 & 1 & 1 & 0.163 \\
\hline LAP-1 & 0.095 & 0.064 & 0.031 & 0.327 & 0.964 & 0.957 & 0.181 \\
\hline 6PGD-1 & 0.091 & 0.083 & 0.008 & 0.088 & 1 & 1 & 0.629 \\
\hline GOT-2 & 0.036 & 0.026 & 0.009 & 0.273 & 1 & 1 & 0.142 \\
\hline GOT-3 & 0.473 & 0.176 & 0.298 & 0.628 & 0.998 & 0.994 & 0.635 \\
\hline SKDH-1 & 0.334 & 0.266 & 0.063 & 0.204 & 1 & 1 & 0.355 \\
\hline PGM-2 & 0.490 & 0.109 & 0.381 & 0.776 & 0.986 & 0.942 & 0.768 \\
\hline ME-1 & 0.117 & 0.102 & 0.014 & 0.125 & 1 & 1 & 0.081 \\
\hline MEAN & 0.123 & 0.072 & 0.051 & 0.414 & 0.994 & 0.991 & 0.454 \\
\hline
\end{tabular}


Skibinski et al. (1984) calculate $\mathrm{F}_{\mathrm{ST}}$ parameter for 299 samples of Lens culinaris ssp. culinaris reaching lower values $(0.314)$ to the ones found in the present study. Taking into account that allogamy percentage is very little in this species, the fact that population differentiation is slightly lower in our study in comparison to strict autogamous plants, cannot be justified. $\mathrm{F}_{\mathrm{ST}}$ values for loci GOT-3 and PGM-2 are the highest, reinforzing the idea that these isozymes are the ones that better discriminate among populations. A possible explanation might be that local varieties sample area in the present study is small and there might have been a material exchange between farmers in local markets.

The dendogram shown in figure 2 , reveals the formation of 4 population groups. One of them would be formed by 14 Pardina lentil populations and the second one would had only one population, 4246. A third group would have three Macrosperma seed landraces, and the fourth group would have Verdina and Macrosperma populations.

Each group has been characterized based on the isozymes that, according to the principal component analysis, have a higher importance in the first factor. GOT-3A, GOT$3 \mathrm{~B}$ and PGM-2A were the most important variables that explain the $22.78 \%$ of the variance. GOT-2A and GOT-3A explain $17.69 \%$ of variance and $40.74 \%$ of accumulated variance. The first group is characterized because allele B of GOT-3 and allele A of PGM-2 are bounded or more frequent. Alleles A of GOT-3 y PGM- 2 are the most frequent in population 4246 (Verdina lentil). Group 3 would have alleles B in both loci bounded or more frequent. The fourth group is made by populations that present alleles A for GOT3 and allele B for PGM- 2 more frequent. The 4 population groups obtained by the dendogram are defined by the GOT3 and PGM-2 allele combinations. Microsperma and Macrosperma lentil characterization based on isozymes GOT-3 and PGM-2 was found too in naturalized lentil germplasm in Chile (Rodríguez et al., 1999).

This lentil germplasm analyzed by isozyme markers, revealed a large genetic diversity in the accessions studied, although it came from a relatively small area, agreeing with the results found about the high variation present in different origins lentil accessions. The results of characterization with isozymes presented here will provide useful information to complement that one stem from characterizations carried out with morphological and molecular markers towards their potential use to develop new lentil varieties in Spain, where local materials are represented by old landraces and registered varieties are lacking.

Our data also showed that isozyme markers are a valuable tool for the characterization of these landraces. In addition it may contribute to the detection of redundant materials and selective acquisition of unique new accessions.

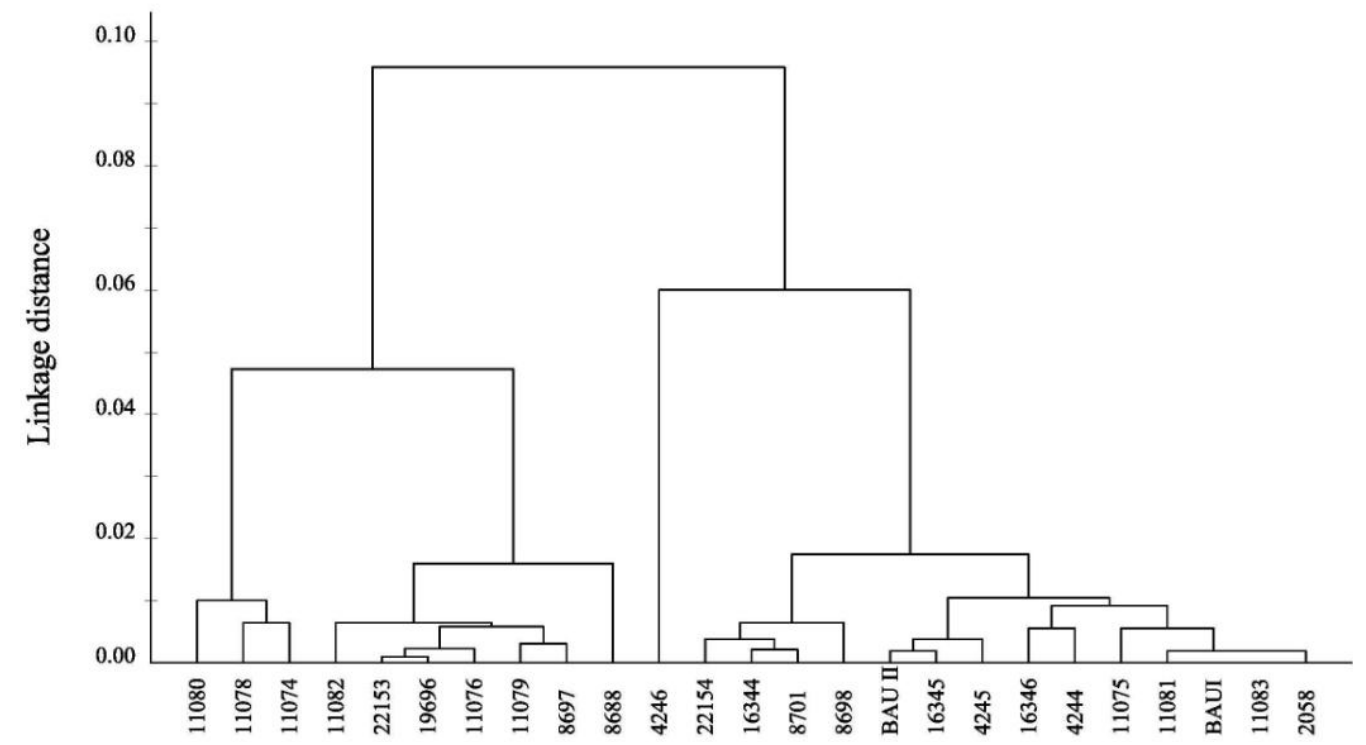

Fig 2: Dendogram that shows the four population groups in which the 25 studied lentil populations are separated.

\section{REFERENCES}

Andeden, E.E., Baloch, F.S., Cadir, E., Toklu, L. and Ozkan, H. (2015). Development, characterization and mapping of microsatellite markers for lentil (Lens culinaris Medik.). Plant Breed. 134: 589-598

Bacchi, M., Leone, M., Mercati, F., Preiti, G., Sunseri, F. and Monti, M. (2010). Agronomic evaluation and genetic characterization of different accessions in lentil (Lens culinaris Medik.). Ital. J. Agron. 4: 303-314.

Brown, A.H.D. (1989). Core collection: a practical approach to genetic resources management. Genome 31: 818-824. 
Cardy, B.J., Stuber, C.W. and Goodman, M.M. (1980). Techniques for starch gel electrophoresis of enzymes from maize (Zea mays L.). North Carolina State University, Raleigh.

Erdogan, C. 2015. Genetic characterization and cotyledon color in lentil. Chil. J. Agr. Res. 75: 383-389.

Erskine, W. and Muelhbauer, F.J. (1991). Allozyme and morphological variability, outcrossing rate and core collection formation in lentil germplasm. Theor. Appl. Genet. 83: 119-125.

Ferguson, M.E. and Robertson, L.D. (1996). Genetic diversity and taxonomic relationships within the genus Lens as revealed by allozyme polymorphism. Euphytica 91: 163-172.

Ferguson, M.E., Ford-Lloyd, B.V., Robertson, L.D. and Maxted, N. (1998). Mapping the geographical distribution of genetic variation in the genus Lens for the enhance conservation of plant genetic diversity. Mol. Ecol. 7: 1743-1755.

Hamrick, J.L. and Godt M.J.W. (1997). Allozyme diversity in cultivated crops. Crop Sci. 37: 26-30.

Jains, S., Porter, L.D., Kumar, A., Mir, R.R., Eigenbrode, S.D. and McPhee, K.E. (2014). Molecular and phenotypic characterization of variation related to pea enation mosaic virus resistance in lentil (Lens culinaris Medik.). Can. J. Plant Sci. 94: 1333-1344.

Lázaro, A. and Aguinagalde, I. (2006). Genetic variation among Spanish pea landraces revealed by Inter Simple Sequences Repeat (ISSR) markers: its application to establish a core collection. J. Agr. Sci. 144: 53-62.

Pérez-Vega, M. and García, P. (1997). Genetic structure of self-pollinating species: the case of wild Avena. Bocconea 7: $141-152$.

Pinkas, R., Zamir, D. and Ladizinsky, G. (1985). Allozyme divergence and evolution in the genus Lens. Plant Syst. Evol. 151: $131-140$.

Rodríguez, M.M., Paredes, M.C. and Becerra, V. (1999). Diversidad isoenzimática del germoplasma de lentejas (Lens culinaris Medik.) naturalizado en Chile. Agricultura Técnica 59: 186-195.

Rosa, L. and Jouve, N. (1992). Genetic variation for isozyme genes and proteins in Spanish primitive cultivars and wild subspecies of Lens. Euphytica 59: 181-187.

Selander, K., Smith, M.H., Yangw, S.Y., Johnson, E. and Gentry, J.B. (1971). Biochemical polymorphism and systematics in the genus Peromyscus. I. Variation in the old-fieldmouse (Peromyscus polionotus). Stud. Genet. 7103: 49-90.

Sharma, K., Mishra, A.K. and Mishra, R.S. (2008). The genetic structure of taro, a comparision of RAPD and isozyme markers. Plant Biotechnol. Rep. 2: 191-198.

Skibinski, D.O.F., Rasool, D. and Erskine, W. (1984). Aspartate aminotransferase allozyme variation in a germplasm collection of the domesticated lentil. Theor. Appl. Genet. 68: 441-448.

SPSS (2006). SPSS 15.0 Brief Guide. SPSS Inc., Chicago.

Tahir, M. and Muehlbauer, F.J. (1995). Association of quantitative trait loci with isozyme markers in lentil. J. Genet. Breed. 49: 145-150.

Yeh, F., Yang, R. and Boyle, T. (1999). POPGENE version 1.31. University of Alberta, Edmonton.

Zohary, D. and Hopf, M. (1994). Domestication of plants in the Old World. $2^{\text {nd }}$ edition. Oxford University Press, Oxford. 